\title{
Meaning and Dialogue Coherence: A Proof-theoretic Investigation
}

\section{Paul Piwek}

\section{Erratum to: J Log Lang Inf (2007) DOI 10.1007/s10849-007-9046-1}

Due to a technical failure, the received date for this article is wrong. The date should read: Received 7 February 2007.

The online version of the original article can be found under doi:10.1007/s10849-007-9046-1. 